\title{
Role of Dental Counselling in Improving Communication Skills
}

\author{
Sandhya Rani Tammareddy리 Karthik Sai Lakshman Yedavallu², Poorna Bhavana Meka ${ }^{3}$ \\ 1, 2 Department of English (Interdisciplinary), Koneru Lakshmaiah Education Foundation, \\ Vaddeswaram, Andhra Pradesh, India. ${ }^{3}$ Department of Public Health \& Dentistry, \\ Government Dental College \& Hospital, Vijayawada, Andhra Pradesh, India.
}

\section{ABSTRACT}

\section{BACKGROUND}

Communication plays a very important role in getting a job. Students must communicate properly to get a job. Students have pre assumed notions related to their appearance (apart from outfit) when they communicate with others. Sometimes, these notions become barriers for them to communicate. Proper analysis should be done to know the root cause for the barriers. Solution will be provided to students to overcome the problem. The aim of this study was to evaluate the importance of dental counselling in improving communication skills of students.

\section{METHODS}

A questionnaire was administered through an online survey. The survey was conducted among 2000 engineering students to study and determine oral problems and their influence on students when they communicate.

\section{RESULTS}

The present study revealed that majority of students do not have proper understanding about their mouth. Wrong notions about oral problems are drawn, and these problems are generalised. As oral problem is also one of the physical barriers, dental counselling is required for all students.

\section{CONCLUSIONS}

Dental counselling helps students not only to maintain oral hygiene but also for improving confidence, which is very important for communication. As it is highly impossible to all students to go to a dentist to get awareness, institutions must arrange community dental awareness programmes in their institutions to improve students' communication skills.

\section{KEY WORDS}

Communication, Barriers, Oral Problems, Counselling, Behaviour, Process, PreAssumed Notions, Students, Awareness
Corresponding Author: Dr. T. Sandhyarani, Assistant Professor KL University, Vaddeswaram, Andhrapradesh - 522502, India. E-mail: sandhyarani.tammareddy@gmail.com DOI: $10.14260 /$ jemds/2021/61

How to Cite This Article: Tammareddy SR, Yedavallu KSL, Meka PB. Role of dental counselling in improving communication skills. J Evolution Med Dent Sci 2021;10(05):273-278, DOI: $10.14260 / \mathrm{jemds} / 2021 / 61$

Submission 20-09-2020,

Peer Review 03-12-2020,

Acceptance 10-12-2020,

Published 01-02-2021.

Copyright (c) 2021 Sandhya Rani Tammareddy et al. This is an open access article distributed under Creative Commons Attribution License [Attribution 4.0 International (CC BY 4.0)] 


\section{BACKGROUND}

Communication is very important in everyone's life. Since man is a social animal, communication is an inevitable process in this globalised world. Life without communication is highly impossible. Communication is a continuous and lifelong process. Communication helps to share ideas, opinions, feelings and emotions. Communication plays a vital role in getting employment.

As per the India skills report 2020, "employability of India's youth has remained stagnant for the past three years, lingering around $46 \%$ of participants who are job-ready. The state of employability has not improved over the last few years, implying the need for more robust actions"1 (pg-19). The same report analysed that the reason for the less employability is due to lack of communication skills.

There are many reasons for the above said problem. The most important reason is lack of confidence. Confidence depends on many factors. The factors may include social, economic, political etc. When students join in professional degree, they must realise that they are all professional students. Irrespective of their background they must improve their communication skills to meet the requirements of job.

In this process of obtaining communication skills, students must build their confidence. They must identify their own problems. Most of the students generalise the problems. This becomes a big hurdle to their success. Instead of generalising all problems, they must think of their own problem. To identify their own problem, a proper guidance is required.

Many institutions are trying to give guidance. As their focus is only providing more facilities to improve communication skills of students, the result is not up to the expectations. Some reports like, India skills report, NITI Aayog report, and Management reports by top companies have warned that the employability skills of the students are not matching industry expectations. ${ }^{1}$ Though India has millions of graduates, only a few graduates are getting the job. The remaining are struggling for years to reach minimum standards of the job's requirements.

Over the years, a lot of research has been done to know the root cause for students' lack of communication skills. The problems are divided into many categories. Each category is analysed in different angles and solutions are also provided. They are all giving better results. However, as per the report given by India skills report 2020, the increased rate of employability skills is only 2 percent. ${ }^{1}$

The reasons for the less growth in employability skills should be identified and a systematic analysis is needed to find the solutions for the problem. All the reports which are mentioned in the above paragraphs stress the importance of communication skills. There is a need to identify the problems of students for not improving their communication skills after providing these many facilities in this modern era.

Studies clearly depicts that there are many barriers to communication. These barriers may occur at any stage of the communication process. The main barriers are physical and psychological. Identification of each problem is very important to give the right solution to overcome the problem.

As research should be narrowed down to get the accurate results, this paper is confined to identify one of the physical barriers, mouth. As mouth plays a very important role in communication, it is necessary to know the problems related to mouth.

Most of the studies explore that the physical problems are related to noise and voice but not mouth. In this paper, the survey is done to do an empirical research to know the problems related to mouth. We also wanted to study the generalised notion of oral problems and its impact on students' communication skills.

Any empirical research requires information related to field which has direct relation with the said problem. This research was related to problems with communication skills. Though communication skills are required for all professional students, most of the professional students are studying engineering, engineering students were chosen for this empirical research. Their opinion was more important to identify the real problem related to mouth in communication skills. To do empirical research, there are many methods to get the information. In this empirical research, survey method was chosen to gather the required data from students.

\section{METHODS}

The survey was conducted in KL University, Andhra Pradesh over a period of seven months, i.e., from February 15, 2020 to Sep 15, 2020. Nearly 2000 undergraduate engineering students participated in the survey. An online questionnaire was distributed to all the students to know the awareness of their oral health and its impact on their communication skills.

The questionnaire was designed to know the awareness of students regarding their oral problems. Lack of awareness is main problem for most of the problems. The questionnaire was also designed in those lines. The main intention of this research was to know whether students can identify their own problem or generalise the topic. When students start generalising the problem, the problems cannot be solved.

If the problem really exists with students, then the suggested solutions for the problem will work out. The questions are designed in such a manner to identify the generalised notion of students in oral problems.

The following questions were given in the questionnaire, students must choose one of the options from the given choices. The questions and the respective answers given by students are shown in the bar graph.

\section{RESULTS}

\section{Question 1 - Do You Think That Oral Problem} is One of the Barriers to Communication?

a) Yes

b) No

This question is asked to know whether students really feel that the oral problem is one of the barriers for communication or not. The response for this question is; out of 1890 students, 99.6 percent chose yes and 0.4 percent chose no. (Graph 1) The result clearly presents that students agree that oral problem is one of the barriers for 
communication. This question leads to the next question to identify what kind of oral problems that students have.

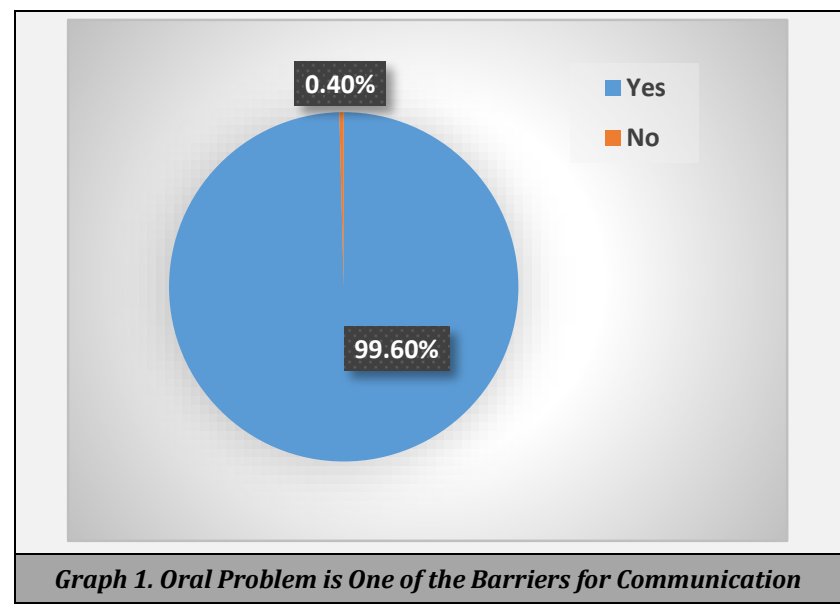

Question 2 - Which of the Following Oral Problems Stops You from Communicating?

- Foul smell

- Ideal teeth set

- Brace

- Colour of gums

- Broken teeth

- Artificial teeth

- Facial alignment

- Yellow pigment on teeth

- Stains on teeth

The second question was designed to know what kind of oral problems that stops them to communicate. Different problems related to mouth were given as choice. Students were not restricted to one choice. Students can select multiple options. Some students selected multiple options also. Graph-2 gives, how much percentage of students suffer with the mentioned oral problem. Though the question is very clear that students must select oral problem that stops them to communicate. The result explores that most of the students selected multiple options. This selection exemplifies that students do not have any idea about oral health and its problems. This is further clarified with next question.

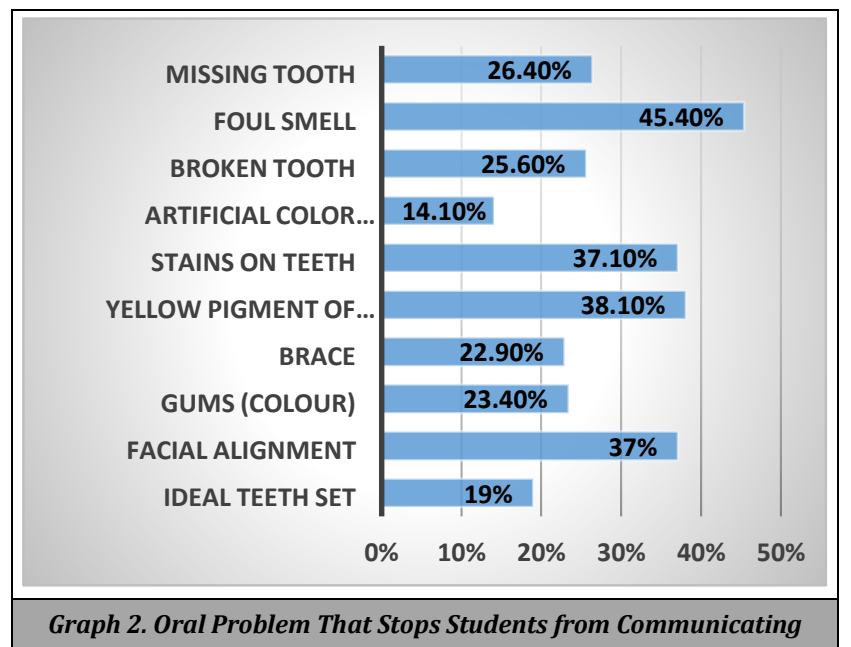

Question 3 - While Selecting the Option for the Above Question, You Have - Generalised and Selected the Option / Identified Your Own Problem

Second question result explores that most of the students have selected multiple answers. The reason should be identified. Without knowing their own problem, on what basis, they have selected options. The analysis is done on what basis students selected the oral problem. Graph 3 . represents that 74 percent of students generalised the problem and 26 percent can identify their own problem.

Generalising oral problem is not a small issue. When students generalise oral problem, they feel that they too have the same problem, and it may act as a barrier for their communication. Students are facing problem because of lack of awareness. Before giving the solution for this problem, identification of reason for generalising the problem is also important. The next question should be designed to know the reason why students generalise the problem.

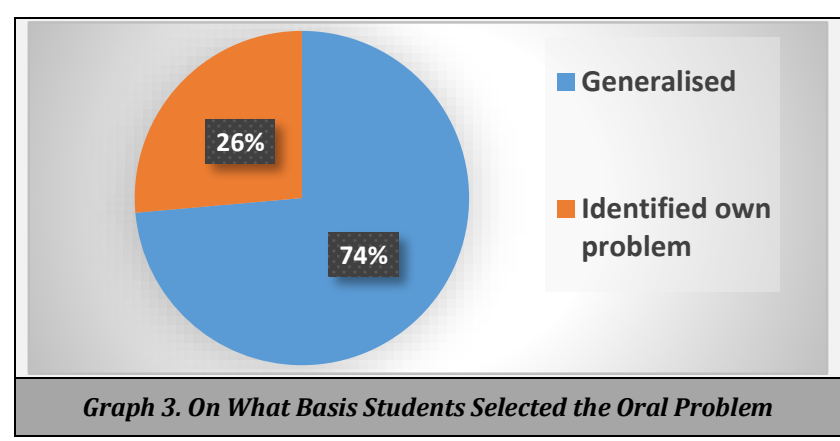

Question 4 - What is the Reason for Generalising the Oral Problem - Lack of Awareness / Pre-Assumed Notions / Not Applicable

The question is designed to get the reason from students for generalising the oral problem. There are different reasons for generalising any idea. As it is related to health, the options are restricted to pre-assumed notions, lack of awareness and not applicable. The result for this question is depicted in graph-4 which shows that 55 percent of students have preassumed notions, 39 percent do not have awareness towards oral problems and 6 percent students chose that options are not applicable. As the problem is identified, the next step is to know the solution for the problem. Next question is designed to know the solution for the problem.

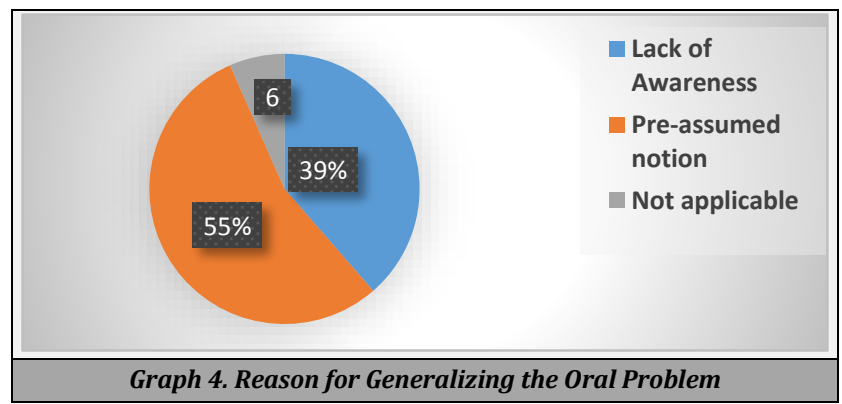




\section{Question 5 - What Solution Do You Prefer to overcome the Oral Problem?}

- Professional dental counselling

- Getting awareness through books and online

- Ignoring the problem

First four question are given to know the problem. From those questions, it was clearly understood that the oral problem is due to generalisation this is mainly due to lack of awareness. Question five was designed to extract a suitable solution opted by students.

The result for the solution is explored in graph 5 , which shows that 74 percent of students required professional dental counselling, 15 percent chose that they can get awareness through books and online, and 11 percent ignored the problem.

Oral problem is related to dental health and lack of awareness is related to counselling; the solution chosen by most of the students was dental counselling. Further, the question was asked to know how far dental counselling helps them to overcome their oral problems in communication skills.

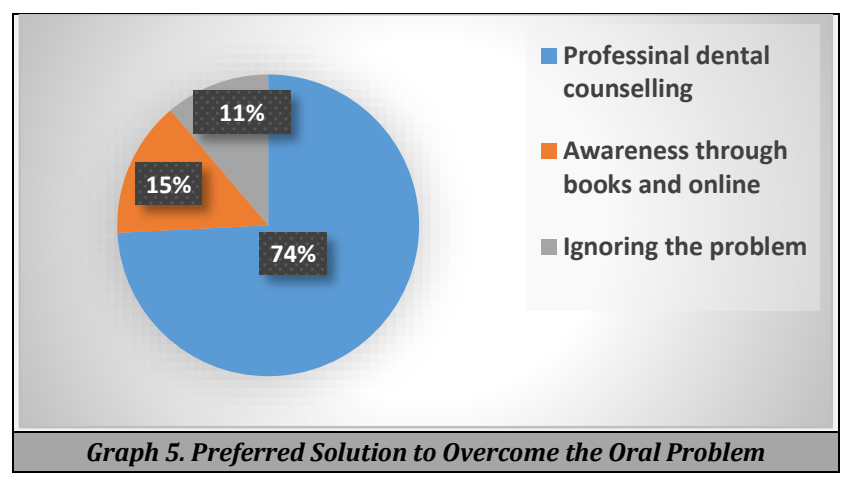

Question 6 - Do You Think That Professional Dental Counselling is Required for Students to Improve Communication Skills?

- Yes

- No

The question is designed to know the importance of dental counselling for professional students especially related to know their oral problem. The result in graph 6 shows that 86 percent agreed that professional dental counselling helps students to improve their communication skills.

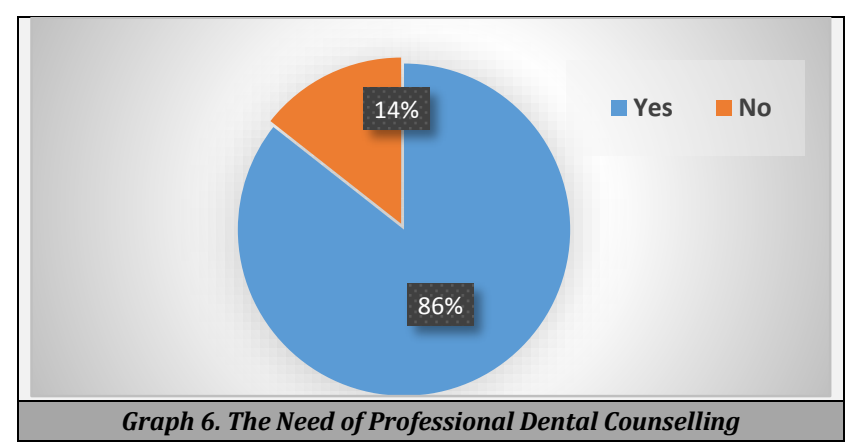

As majority of students opt that professional dental counselling is required to improve their communication skills, there is a need of dental professional counselling in all professional colleges. The qualified professional dentist can only give right counselling to students to identify their own problem and get solution for it. This is further elaborated in the discussion part.

The present study revealed that majority of students do not have proper understanding about their mouth. Wrong notions about oral problems are drawn, and these problems are generalised. As oral problem is also one of the physical barriers, dental counselling is required for all students.

\section{DISCUSSION}

The questions are asked to identify the problem from the students' point of view. As the students are professionals, the expected solution is also extracted from students only. In Indian context, oral health is given least priority, the awareness about oral health is almost negligible. In such a case, there is no chance of students identifying their own problems.

The research questions were also designed to draw answers from students from their known field to unknown. Most of the research related to communication skills is based on improving confidence in students to improve their communication skills. Confidence is built on many issues. One of the issues is oral health and understanding of one's oral conditions and their role in communication skills. If the students are not aware of their mouth and its role in verbal communication skills, they are under wrong impression that they too have the above discussed problems. This wrong assumption may affect their confidence and act as a barrier for their communication skills.

The systematic empirical research and its result reveals that the mouth is one of the physical barriers for communication. As most of the students are unaware of their own problems, they have generalised the problem and feel that they too have those problems. Proper dental counselling helps students to know their own problems and should go for treatment if it is required.

The World Health Organization (WHO) opined that health education is important for people to get control over their own health. ${ }^{5}$ It also emphasises that health education should be a part of people's everyday life, rather than focusing on people at risk for specific diseases. ${ }^{2}$ The WHO suggests that proper guidance and counselling to community helps people to know their problem and can live a happy live without discomfort. ${ }^{2}$ If this kind of suggestion is implemented, there can be a clear change in people's lives.

The WHO has defined different health policies in its report. All these policies are applicable in different regions and communities. As this paper is related to oral problems, the definition of oral health is taken into consideration. ${ }^{2}$

The WHO opined that oral health enables an individual to speak without active disease, discomfort, or embarrassment. Disease can be diagnosed, whereas discomfort and embarrassment can be removed only through proper counselling. ${ }^{2}$ The WHO entire health report stresses the importance of health counselling for all people. ${ }^{2}$ 
This paper studied an issue related to oral problems in a survey form. The survey results clearly showed the preassumed notions of students about their oral health and its related issues in communication. These notions can be removed only when oral health education promotion activities are conducted in all educational institutions.

Pre-assumed notions are related to behavioural issue. Behaviour of any person depends upon the society and his experience and practice on issue over years. It is highly impossible to expect instant change among anyone especially among students. Step by step process is required to remove deeply rooted opinions. This process is explained with the help of Prochaska and DiClemente's, The Transtheoretical Model (also called the stages of change model) developed in 1970s. This model clearly identifies different stages involved in the change of behaviour. ${ }^{3}$ (Figure 1 )

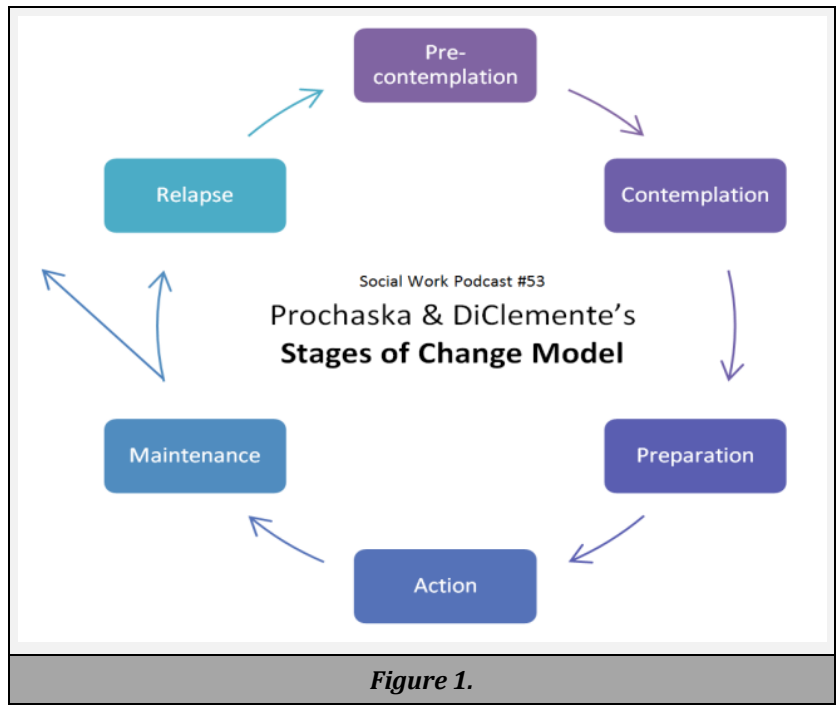

\section{Pre-Contemplation Stage}

Students are unaware that oral problem is one of the physical barriers of communication. When problem is not identified, there is no chance of changing behaviour. Generally, students may not be under this stage. Their education gives an idea about the problems that they face in their lives.

\section{Contemplation Stage}

The survey shows that students already know that oral problem is one of the barriers to communication. This makes the research very easy. Students can identify the problem. When the participants are able to identify their own problem, it will be very easy to suggest a solution.

\section{Preparation}

The problem is with professional students and related to communication skills, organisations or institutions must take initiation to conduct dental counselling to students to come out of their wrong notions and believes related to oral problems. At this stage students can identify their own problem and think of changing their behaviour.

\section{Action}

As per Robert Ireland, dental professionals, “...can see that their role is to support natural processes of change. Intervention to promote health behaviour change might be better seen as supported self-help rather than treatment"4(143). This kind of approach helps students to come out of their wrong notions and should understand their own issues rather than generalising the problems. One to one counselling may not help students, community awareness is the best solution for generalised problems.

\section{Maintenance}

Generalisation is a natural process in society. The awareness given in the action can be maintained only when proper counselling sessions are conducted in action stage. According to Bradshaw, dental counsellors should focus on normative need and should plan according to that before conducting counselling sessions for students. This helps students to overcome the generalised notions and know about their own problem. ${ }^{5}$ If the oral problem really exists with students, they may solve it by consulting a dentist. If they do not have any issue related to oral health, they are free from all pre assumed notions. It helps them in building their confidence. Confidence is very important for communication skills. This helps them to achieve their goals very quickly.

\section{Relapse}

There is a possibility of relapsing the entire process and coming back to original stage. This can be avoided with a strong foundation by professional dental counsellors. Counselling should be given to understand the wrong believes and values which effect their feelings. If this is done relapse can be avoided. Repeated counselling should be conducted to avoid relapse. Three or four institutional counselling sessions help students not to come to this stage. They know the importance of health education in general and oral health education in particular.

\section{CONCLUSIONS}

The survey reveals that students have many pre-assumed notions related to oral problems. These notions act as physical barrier to them when they communicate with others. Proper counselling is required. As it is highly impossible for students to go to dental clinics to get awareness, the institutions must organise dental counselling for all students in the campus by a professional dentist. Though oral problems seem to be ignorable, they play a major role in confidence building which is very essential for communication. Proper guidelines by a dentist can only give awareness to students about oral problems and its impact on their communication skills.

\section{Further Research}

The problem is identified, and solution is also suggested to overcome the oral problem and to build the confidence. Further research can be done after conducting the dental counselling to students. How far dental counselling helps 
students to improve confidence should be known by doing an empirical research. This research also can be done through survey form. If this solution yields good results, there can be a drastic change among students. The WHO suggestions are also fulfilled. ${ }^{2}$

Data sharing statement provided by the authors is available with the full text of this article at jemds.com.

Financial or other competing interests: None.

Disclosure forms provided by the authors are available with the full text of this article at jemds.com.

\section{REFERENCES}

[1] https://wheebox.com/assets/pdf/ ISR_Report_2020.pdf. Accessed on 14, Oct, 2020.

[2] World Health Organization 2005. WHO Secretariat background document for the $6^{\text {th }}$ Global Conference on Health Promotion. Bangkok, Thailand. Global Health Promotion: Scaling Up for 2015- a brief review of major impacts and developments over the last 20 years and challenges for 2015.

[3] Prochaska J0, DiClemente CC. Self-change processes, self efficacy and decisional balance across five stages of smoking cessation. ProgClinBiol Res1984; 156:131-40.

[4] Ireland R. Clinical Textbook of Dental Hygiene and Therapy.UK: Blackwell Publishing House 2006.

[5] Bradshaw J. The concept of social need. New Society 1972;19:640-3 